DOI : https://doi.org/10.24843/JFU.2020.v09.i01.p06

pISSN: 2301-7716; eISSN: 2622-4607

Jurnal Farmasi Udayana, Vol 9, No 1, Tahun 2020, 37-44

\title{
Evaluasi Penggunaan Antibiotik pada Pasien Tifoid Rawat Inap di Salah Satu Rumah Sakit Pemerintah Provinsi Bali dengan Metode Gyssens dan ATC/DDD
}

\author{
Sukmawati, I.G.A.N.D. ${ }^{1}$, Jaya, M.K.A. ${ }^{1 *}$, Swastini, D.A. ${ }^{1}$ \\ ${ }^{1}$ Program Studi Farmasi, Fakultas Matematika dan Ilmu Pengetahuan Alam, Universitas Udayana, Jalan Kampus Unud, \\ Jimbaran, 80364 \\ *E-mail: krisnaadijaya@unud.ac.id
}

Riwayat artikel: Dikirim: 23/04/2020; Diterima: 02/06/2020, Diterbitkan: 25/06/2020

\begin{abstract}
Typhoid is a global health problem especially in developing countries, one of which is in Indonesia. The incidence of antibiotic resistance in typhoid therapy can occur due to inappropriate use of antibiotics. This study aims to determine patterns of antibiotic use as well as the quality and quantity of antibiotic use in typhoid therapy in one of the provincial government hospitals in Bali. This study was an observational study conducted retrospectively which was analyzed using the Gyssens and ATC/DDD methods. The research data were taken from the medical records of patients in the January-December 2019 period that met the inclusion criteria. The results showed that of the 40 total antibiotics prescribing, ceftriaxone was the most widely used antibiotic for typhoid therapy. The quality of antibiotic use as much as $40 \%$ is stated rational (category 0 ), while the other $60 \%$ is irrational (categories I-VI) which includes the use of antibiotics with incorrect interval of administration (IIB; $5 \%$ ), the use of antibiotics that is too long (IIIA; 40\%), the use of antibiotics that are too short (IIIB; $5 \%$ ), there are other antibiotics that are more effective (IVA; $5 \%$ ), and there are other antibiotics that are less toxic/safer (IVB; $5 \%$ ). The quantity of antibiotic use was stated more than WHO standards which includes the use of ceftriaxone at $83.80 \mathrm{DDD} / 100$ patient days; levofloxacin at $27.47 \mathrm{DDD} / 100$ patient days; and azithromycin at 3.52 DDD/100 patient days. The results of this study are expected to be a consideration for the hospital as a material for evaluation and improvement in order to improve the rationality of antibiotic use.
\end{abstract}

Keywords: Antibiotics, Typhoid, Gyssens, ATC/DDD

\begin{abstract}
ABSTRAK
Tifoid merupakan permasalahan kesehatan global terutama di negara berkembang, salah satunya di Indonesia. Kejadian resistensi penggunaan antibiotik pada terapi tifoid dapat terjadi akibat penggunaan antibiotik yang tidak tepat. Penelitian ini bertujuan untuk mengetahui pola penggunaan antibiotik serta kualitas dan kuantitas penggunaan antibiotik pada terapi tifoid di salah satu rumah sakit pemerintah Provinsi Bali. Penelitian ini merupakan penelitian observasional yang dilakukan secara retrospektif yang dianalisis menggunakan metode Gyssens dan ATC/DDD. Data penelitian diambil dari rekam medis pasien periode Januari-Desember 2019 yang memenuhi kriteria inklusi. Hasil penelitian menunjukkan bahwa dari 40 total peresepan antibiotik, seftriakson merupakan antibiotik yang paling banyak digunakan untuk terapi tifoid. Kualitas penggunaan antibiotik sebanyak 40\% dinyatakan rasional (kategori 0 ), sedangkan $60 \%$ lainnya tidak rasional (kategori I-VI) yang meliputi penggunaan antibiotik tidak tepat interval pemberian (IIB; 5\%), penggunaan antibiotik yang terlalu lama (IIIA; 40\%), penggunaan antibiotik yang terlalu singkat (IIIB; 5\%), terdapat antibiotik lain yang lebih efektif (IVA; 5\%), dan terdapat antibiotik lain yang kurang toksik/lebih aman (IVB; 5\%). Kuantitas penggunaan antibiotik dinyatakan melebihi standar WHO yaitu pada penggunaan seftriakson sebesar 83,80 DDD/100 patient days; levofloxacin sebesar 27,47 DDD/100 patient days; dan azitromisin sebesar 3,52 DDD/100 patient days. Hasil penelitian ini diharapkan dapat menjadi pertimbangan bagi pihak rumah sakit sebagai bahan evaluasi dan perbaikan dalam rangka meningkatkan rasionalitas penggunaan antibiotik.
\end{abstract}

Kata kunci: Antibiotik, Tifoid, Gyssens, ATC/DDD 
DOI : https://doi.org/10.24843/JFU.2020.v09.i01.p06

pISSN: 2301-7716; eISSN: 2622-4607

Jurnal Farmasi Udayana, Vol 9, No 1, Tahun 2020, 37-44

\section{PENDAHULUAN}

Tifoid merupakan penyakit menular yang disebabkan oleh bakteri Salmonella typhi. Pasien tifoid memiliki gejala klinis yaitu demam yang diikuti dengan mual, muntah, anoreksia, dan diare (Adiputra dan Somia, 2017). Tifoid merupakan permasalahan kesehatan global, dimana diperkirakan 11-20 juta orang mengidap tifoid dan 128.000 hingga 161.000 diantaranya meninggal setiap tahunnya (WHO, 2018). Kasus tifoid yang terjadi di Asia Tenggara mencapai 14,1\% dari kasus tifoid secara global (GBD Typhoid and Paratyphoid Collaborators, 2017). Kasus tifoid di Indonesia menunjukkan adanya kecenderungan peningkatan dari tahun ke tahun dengan rata-rata kesakitan 500/100.000 penduduk dan kematian diperkirakan sekitar 0,6-5\% (Purba dkk., 2016).

Pilihan terapi yang tepat untuk tifoid yang disebabkan oleh bakteri Salmonella typhi adalah menggunakan antibiotik. Penggunaan antibiotik yang tidak tepat akan menimbulkan peningkatan kejadian bakteri yang resisten terhadap antibiotik termasuk Salmonella typhi. Kasus resistensi Salmonella typhi terhadap kloramfenikol pertama kali dilaporkan pada tahun 1974. Kasus resistensi bakteri ini juga terjadi pada tahun 1994 terhadap berbagai jenis antibiotik yaitu kloramfenikol, ampisilin, dan trimethoprim-sulfametoksazol, atau dikenal sebagai Multiple Drug Resistance (MDR) (Alam, 2011). Masalah resistensi bakteri terhadap antibiotik ini sudah menjadi masalah kesehatan di seluruh dunia, untuk itu perlu dilakukan monitoring dan evaluasi penggunaan antibiotik di rumah sakit secara sistematis dan terstandar serta penggunaan antibiotik secara rasional (Megawati, 2015).

Evaluasi penggunaan antibiotik merupakan salah satu indikator mutu Program Pengendalian Resistensi Antimikroba (PPRA) di rumah sakit yang bertujuan untuk memberikan informasi pola penggunaan antibiotik di rumah sakit baik kualitas maupun kuantitas. Kualitas penggunaan antibiotik dapat dinilai dengan menggunakan metode Gyssens (Kemenkes RI, 2015). Evaluasi penggunaan antibiotik dengan metode Gyssens bertujuan untuk menilai ketepatan penggunaan antibiotik dimana antibiotik digolongkan menjadi kategori 0 (penggunaan rasional) dan kategori I hingga VI (penggunaan tidak rasional) (Sitompul dkk., 2016). Dalam evaluasi penggunaan antibiotik secara kuantitatif, World Health Organization (WHO) merekomendasikan evaluasi penggunaan antibiotik dengan menggunakan metode ATC/DDD (Pani dkk., 2015). Metode ini bertujuan untuk mengklasifikasi penggunaan antibiotik menurut Anatomical Therapentic Chemical (ATC) dan mengukur jumlah penggunaan antibiotik dengan Defined Daily Dose (DDD/100 patient days berdasarkan standar yang ditetapkan oleh WHO (Kemenkes RI, 2015).

Penelitian terkait evaluasi penggunaan antibiotik tifoid berdasarkan metode Gyssens maupun ATC/DDD belum pernah dilakukan di Provinsi Bali. Berdasarkan uraian di atas, maka perlu dilakukan suatu penelitian untuk mengevaluasi penggunaan antibiotik pada kasus tifoid dengan menggunakan metode Gyssens dan ATC/DDD. Dalam penelitian ini diharapkan agar hasil evaluasi penggunaan antibiotik dapat menjadi masukan dan alternatif pemilihan obat antibiotik yang efektif pada kasus tifoid.

\section{BAHAN DAN METODE}

\section{Alat dan Bahan}

\section{Alat}

Lembar pengumpul data, gyssens flowchart, dan guidelines for ATC Classification and DDD Assignment.

\section{Bahan}

\section{Metode}

Rekam medis pasien pada tahun 2019.

Penelitian ini merupakan penelitian yang bersifat non eksperimental (observasional) yang dianalisis menggunakan metode Gyssens dan ATC/DDD terhadap pasien tifoid yang mendapatkan antibiotik. Pengambilan data dilakukan secara retrospektif melalui rekam medis pasien di rumah sakit untuk mengevaluasi rasionalitas penggunaan antibiotik secara kualtitatif dan kuantitatif.

\section{Tempat dan waktu penelitian}

Penelitian dilakukan di bagian rekam medik di salah satu rumah sakit pemerintah Provinsi Bali 
DOI : https://doi.org/10.24843/JFU.2020.v09.i01.p06

pISSN: 2301-7716; eISSN: 2622-4607

Jurnal Farmasi Udayana, Vol 9, No 1, Tahun 2020, 37-44

pada bulan Februari 2020. Pelaksanaan penelitian dinyatakan layak etik dan telah mendapatkan ethical clearance dengan nomor 95/UN14.2.2.VII.14/LP/2020.

\section{Kriteria inklusi dan eksklusi pasien}

Kriteria inklusi pasien meliputi pasien yang didiagnosis tifoid yang dirawat inap di salah satu rumah sakit pemerintah Provinsi Bali pada bulan Januari hingga Desember 2019, pasien rawat inap tifoid yang mendapat terapi antibiotik untuk tifoid, pasien dewasa yang berusia 18-59 tahun, serta data rekam medis yang lengkap yang meliputi nomor rekam medis, umur pasien, jenis kelamin, berat badan, tinggi badan, riwayat penyakit, riwayat penggunaan obat, LOS, jenis antibiotik, dosis, rute pemberian, frekuensi pemberian, dan lama pemberian antibiotik. Kriteria eksklusi pasien adalah pasien tifoid dengan penyakit kritis seperti gagal ginjal, penyakit jantung, sirosis hepatik serta pasien tifoid yang dirawat inap yang disertai penyakit infeksi selain tifoid.

\section{Pengambilan data pasien}

Rekam medis yang memenuhi kriteria inklusi diambil data yang meliputi informasi tentang nomor rekam medis, umur pasien, jenis kelamin, berat badan, tinggi badan, riwayat penyakit, riwayat penggunaan obat, Length of Stay (LOS), jenis antibiotik, dosis, rute pemberian, frekuensi pemberian, dan lama pemberian. Data yang telah dikumpulkan pada lembar pengumpul data diperiksa kelengkapan data untuk memudahkan pengolahan data. Data kemudian diolah dengan membagi data berdasarkan pengelompokkan data kualitatif dan kuantitatif. Data kualitatif meliputi sosiodemografi pasien, LOS, pola penggunaan antibiotik, data evaluasi penggunaan antibiotik dengan metode Gyssens. Data kuantitatif dalam penelitian ini akan disajikan secara analitik berupa data yang digunakan untuk mengevaluasi rasionalitas antibiotik secara kuantitatif yang akan diukur berdasarkan metode ATC/DDD.

\section{Analisa data}

Analisa data dilakukan secara kualitatif dan kuantitatif. Analisa kualitatif dilakukan secara deskriptif dengan menguraikan data kualitatif meliputi data sosio demografi pasien, data LOS, data pola penggunaan antibiotik, dan data evaluasi antibiotik dengan Gyssens. Evaluasi penggunaan antibiotik dengan metode Gyssens dianalisa berdasarkan tahapan pada Gyssens Flowchart. Dalam tahapan analisis ini akan diketahui hasil evaluasi kualitas penggunaan antibiotik tifoid yang dikelompokkan menjadi kategori 0 hingga kategori VI. Antibiotik yang termasuk ke dalam kategori 0 merupakan antibiotik yang penggunaannya dinyatakan rasional, sedangkan pada kategori I hingga VI penggunaan antibiotik dinyatakan tidak rasional. Analisa kuantitatif dilakukan dengan menggunakan metode ATC/DDD yaitu klasifikasi antibiotik dengan pemberian kode yang berdasarkan sistem Anatomical Therapeutic Chemical dan pengukuran penggunaan antibiotik untuk memperoleh nilai DDD/100 patients days menggunakan Defined Daily Dose yang berdasarkan guideline yang dikeluarkan oleh WHO.

\section{HASIL}

Data yang diteliti sebanyak 36 rekam medis pasien dewasa dengan tifoid yang memenuhi kriteria inklusi di salah satu rumah sakit pemerintah Provinsi Bali pada bulan Januari hingga Desember 2019. Distribusi pasien tifoid kategori umur dewasa berdasarkan sosiodemografi dapat dilihat pada Tabel 1. 


\section{Sukmawati dkk.}

DOI : https://doi.org/10.24843/JFU.2020.v09.i01.p06

pISSN: 2301-7716; eISSN: 2622-4607

Jurnal Farmasi Udayana, Vol 9, No 1, Tahun 2020, 37-44

Tabel 1. Sosio demografi Pasien Rawat Inap Dewasa Tifoid di Salah Satu Rumah Sakit Pemerintah Provinsi Bali Tahun 2019

\begin{tabular}{|c|c|c|c|}
\hline Karakteristik & & Jumlah & Persentase $(\%)$ \\
\hline \multicolumn{4}{|l|}{ Kelompok Usia } \\
\hline 1. $18-24$ tahun & & 12 & 33,33 \\
\hline 2. 25-31 tahun & & 8 & 22,22 \\
\hline 3. $32-38$ tahun & & 8 & 22,22 \\
\hline 4. $39-45$ tahun & & 5 & 13,89 \\
\hline 5. $46-52$ tahun & & 2 & 5,56 \\
\hline \multirow[t]{2}{*}{ 6. 53-59 tahun } & & 1 & 2,78 \\
\hline & Total & 36 & 100 \\
\hline \multicolumn{4}{|l|}{ Jenis Kelamin } \\
\hline 1. Laki-laki & & 12 & 33,33 \\
\hline \multirow[t]{2}{*}{ 2. Perempuan } & & 24 & 66,67 \\
\hline & Total & 36 & 100 \\
\hline \multicolumn{4}{|l|}{ Indeks Massa Tubuh } \\
\hline 1. Kekurangan berat badan tingkat berat $(<17,0)$ & & 1 & 2,77 \\
\hline 2. Kekurangan berat badan ringan $(17,0-18,4)$ & & 1 & 2,77 \\
\hline 3. Normal $(18,5-25,0)$ & & 27 & 75,02 \\
\hline 4. Kelebihan berat badan tingkat ringan $(25,1-27,0)$ & & 3 & 8,33 \\
\hline \multirow[t]{2}{*}{ 5. Kelebihan berat badan tingkat berat $(>27,0)$} & & 4 & 11,11 \\
\hline & Total & 36 & 100 \\
\hline \multicolumn{4}{|l|}{ Riwayat Penyakit } \\
\hline 1. Tidak punya & & 27 & 75 \\
\hline 2. Diabetes Melitus & & 2 & 5 \\
\hline \multirow[t]{2}{*}{ 3. Penyakit lainnya } & & 7 & 20 \\
\hline & Total & 36 & 100 \\
\hline \multicolumn{4}{|l|}{ Riwayat Pengobatan } \\
\hline 1. Tidak punya & & 19 & 45 \\
\hline 2. Parasetamol & & 11 & 26 \\
\hline 3. Cefixime & & 3 & 7 \\
\hline 4. Omeprazol & & 3 & 7 \\
\hline 5. Metformin & & 2 & 5 \\
\hline \multirow[t]{2}{*}{ 6. Pengobatan lainnya } & & 4 & 10 \\
\hline & Total & 42 & 100 \\
\hline
\end{tabular}

Pada Tabel 2 menunjukkan hasil jumlah LOS Pasien Rawat Inap Dewasa Tifoid yang man asebagian besar 4-6 hari. Sebagian kecil memerlukan waktu LOS selama 7-9 hari.

Tabel 2. Distribusi Length of Stay Pasien Rawat Inap Dewasa Tifoid di Salah Satu Rumah Sakit Pemerintah Provinsi Bali Tahun 2019

\begin{tabular}{ccc}
\hline Length of Stay (LOS) & Jumlah & Persentase $(\%)$ \\
\hline $1-3$ & 15 & 41,67 \\
$4-6$ & 18 & 50,00 \\
$7-9$ & 3 & 8,33 \\
\hline Total pasien & 36 & 100 \\
\hline
\end{tabular}

Total jumlah peresepan antibiotik untuk terapi tifoid pada penelitian ini adalah 40 peresepan yang meliputi jenis antibiotik seftriakson, levofloxacin, dan azitromisin (Tabel 3). Paling banyak obat yang diresepkan adalan seftriakson. 


\section{Sukmawati dkk.}

DOI : https://doi.org/10.24843/JFU.2020.v09.i01.p06

pISSN: 2301-7716; eISSN: 2622-4607

Jurnal Farmasi Udayana, Vol 9, No 1, Tahun 2020, 37-44

Tabel 3. Pola Penggunaan Antibiotik pada Pasien Dewasa Rawat Inap Tifoid di Salah Satu Rumah Sakit Pemerintah Provinsi Bali Tahun 2019

Karakteristik Jumlah $\quad$ Persentase (\%)

\begin{tabular}{|c|c|c|c|}
\hline \multicolumn{4}{|l|}{ Jenis Antibiotik } \\
\hline 1. Seftriakson & & 24 & 60,00 \\
\hline 2. Levofloxacin & & 14 & 35,00 \\
\hline \multirow[t]{2}{*}{ 3. Azitromisin } & & 2 & 5,00 \\
\hline & Total & 40 & 100 \\
\hline \multicolumn{4}{|l|}{ Rute Pemberian } \\
\hline 1. Intravena & & 36 & 90,00 \\
\hline \multirow{2}{*}{ 2. Oral } & & 4 & 10,00 \\
\hline & Total & 40 & 100 \\
\hline \multicolumn{4}{|l|}{ Frekuensi Pemberian } \\
\hline 1. $1 \times 1$ & & 38 & 95,00 \\
\hline \multirow[t]{2}{*}{ 2. $2 \times 1$} & & 2 & 5,00 \\
\hline & Total & 40 & 100 \\
\hline \multicolumn{4}{|l|}{ Lama Pemberian } \\
\hline 1. 1-3 hari & & 23 & 57,50 \\
\hline 2. 4-6 hari & & 16 & 40,00 \\
\hline \multirow[t]{2}{*}{ 3. 7-9 hari } & & 1 & 2,50 \\
\hline & Total & 40 & 100 \\
\hline
\end{tabular}

Tabel 4. Hasil Evaluasi Ketepatan Penggunaan Antibiotik pada Dewasa Tifoid dengan Metode Gyssens di Instalasi Rawat Inap Salah Satu Rumah Sakit Pemerintah Provinsi Bali Tahun 2019

\begin{tabular}{|c|c|c|c|c|c|c|c|c|c|c|c|c|c|c|c|}
\hline \multirow[t]{3}{*}{ No } & \multirow[t]{3}{*}{ Jenis Antibiotik } & \multicolumn{13}{|c|}{ Kategori Gyssens } & \multirow{3}{*}{$\begin{array}{c}\text { Total } \\
\text { Peresepan }\end{array}$} \\
\hline & & 0 & I & II & II & II & III & III & IV & IV & IV & IV & $\mathrm{V}$ & VI & \\
\hline & & & & $\mathrm{A}$ & B & $\mathrm{C}$ & $\mathrm{A}$ & $\mathrm{B}$ & $\mathrm{A}$ & $\mathrm{B}$ & $\mathrm{C}$ & $\mathrm{D}$ & & & \\
\hline 1 & $\begin{array}{l}\text { Seftriakson } \\
\text { intravena }\end{array}$ & 9 & & & 2 & & 12 & 1 & & & & & & & 24 \\
\hline 2 & $\begin{array}{l}\text { Levofloxacin } \\
\text { intravena }\end{array}$ & 6 & & & & & 4 & & & 2 & & & & & 12 \\
\hline 3 & $\begin{array}{l}\text { Levofloxacin } \\
\text { oral }\end{array}$ & 1 & & & & & & 1 & & & & & & & 2 \\
\hline 4 & $\begin{array}{l}\text { Azitromisin } \\
\text { oral }\end{array}$ & & & & & & & & 2 & & & & & & 2 \\
\hline \multicolumn{2}{|c|}{ Jumlah } & 16 & 0 & 0 & 2 & 0 & 16 & 2 & 2 & 2 & 0 & 0 & 0 & 0 & 40 \\
\hline \multicolumn{2}{|c|}{ Persentase $(\%)$} & 40 & & & 5 & & 40 & 5 & 5 & 5 & & & & & 100 \\
\hline
\end{tabular}

\section{Keterangan:}

Kategori 0 : Penggunaan antibiotik tepat/bijak

Kategori I : Penggunaan antibiotik tidak tepat waktu

Kategori IIA : Penggunaan antibiotik tidak tepat dosis

Kategori IIB : Penggunaan antibiotik tidak tepat interval pemberian

Kategori IIC : Penggunaan antibiotik tidak tepat cara/rute pemberian

Kategori IIIA : Penggunaan antibiotik terlalu lama

Kategori IIIB : Penggunaan antibiotik terlalu singkat

Kategori IVA : Ada antibiotik lain yang lebih efektif

Kategori IVB : Ada antibiotik lain yang kurang toksik/lebih aman

Kategori IVC : Ada antibiotik lain yang lebih murah

Kategori IVD : Ada antibiotik lain yang spektrumnya lebih sempit

Kategori $\mathrm{V}$ : Tidak ada indikasi penggunaan antibiotik

Kategori VI : Data rekam medis tidak lengkap dan tidak dapat dievaluasi 
DOI : https://doi.org/10.24843/JFU.2020.v09.i01.p06

pISSN: 2301-7716; eISSN: 2622-4607

Jurnal Farmasi Udayana, Vol 9, No 1, Tahun 2020, 37-44

Tabel 5. Nilai DDD/100 patient days pada Antibiotik Tifoid pada Pasien Dewasa Rawat Inap di Salah Satu Rumah Sakit Pemerintah Provinsi Bali Periode Januari-Desember 2019

\begin{tabular}{lcccccc}
\hline \multicolumn{1}{c}{ Jenis Antibiotik } & $\begin{array}{c}\text { Kode } \\
\left.\text { ATC }^{*}\right)\end{array}$ & Rute & $\begin{array}{c}\text { Total } \\
\text { Penggunaan } \\
\text { (gram) }\end{array}$ & $\begin{array}{c}\text { DDD } \\
\text { WHO*) } \\
\text { (gram/ } \\
\text { pasien) }\end{array}$ & $\begin{array}{c}\text { DDD } \\
\text { Penggunaan } \\
\text { (pasien) }\end{array}$ & $\begin{array}{c}\text { DDD }) \\
0 \text { patient } \\
\text { days***) }\end{array}$ \\
\hline Seftriakson & J01DD04 & $\mathrm{P}$ & 238 & 2 & 119 & 83,80 \\
Levofloxacin & J01MA12 & $\mathrm{P}$ & 17,5 & 0,5 & 35 & 24,65 \\
Azitromisin & J01FA10 & O & 2 & 0,5 & 4 & 2,82 \\
\hline
\end{tabular}

Keterangan:

P: Parenteral; O: Oral; *) diperoleh dari guideline WHO (2019); **) Total penggunaan/DDD WHO; ***) DDD penggunaan x 100/LOS

\section{PEMBAHASAN}

Berdasarkan jenis kelamin, pasien perempuan memiliki persentase yang lebih tinggi dibandingkan laki-laki. Hal ini dikarenakan berdasarkan daya tahan tubuh, perempuan lebih berpeluang untuk terkena dampak yang lebih berat atau mendapat komplikasi dari tifoid (Dewi, 2018). Salah satu teori menunjukan bahwa Salmonella typhi masuk ke dalam sel-sel hati, maka hormon estrogen pada wanita akan bekerja lebih berat karena mengalami dua hal sekaligus (Pramitasari, 2013).

Length of Stay (LOS) merupakan lama pasien tinggal di rumah sakit untuk mendapatkan perawatan pada penyakit yang diderita sampai dengan pasien tersebut keluar dari rumah sakit (Dewi dkk., 2019). Total Length of Stay pada penelitian ini adalah 142 hari dengan rata-rata lama rawat inap pasien yaitu 4 hari. Pada Tabel 2 diperoleh bahwa LOS terbanyak adalah 4-6 hari dengan persentase $50 \%$. Pasien tifoid kategori umur dewasa idealnya akan mengalami perbaikan klinis dalam 3-7 hari (Melarosa dkk., 2019). LOS dapat dipengaruhi oleh beberapa faktor yang meliputi tingkat keparahan penyakit, efek samping obat, dan kemungkinan pasien sudah mengonsumsi obat sebelum masuk rumah sakit (Dewi dkk., 2019). LOS yang singkat dapat disebabkan karena pasien memiliki kepatuhan terhadap pengobatan dan memperoleh nutrisi yang baik sehingga akan mempercepat lama rawat inap pasien di rumah sakit (Hasnawati dkk., 2014).

Pada Tabel 3 dapat dilihat bahwa seftriakson merupakan jenis antibiotik yang memiliki persentase tertinggi pada penelitian ini sebanyak $60 \%$. Seftriakson memiliki aktivitas anti bakteri gram negatif yang kuat, sehingga memiliki kemampuan dalam menghambat sintesis dinding sel Salmonella typhi (Tjay dan Rahardja, 2007). Rute pemberian antibiotik merupakan salah satu faktor yang dapat menentukan ketepatan penggunaan antibiotik. Rute pemberian intravena memiliki persentase yang lebih tinggi dibandingkan oral karena memiliki onset yang cepat dan bioavailabilitasnya yang lebih baik sehingga efek terapetik obat akan lebih cepat tercapai (Pattatan, 2017). Pada penelitian ini penggunaan antibiotik terbanyak selama 1 sampai 3 hari dikarenakan banyak antibiotik yang diresepkan dengan tujuan sebagai terapi empiris. Pada kasus terapi empiris digunakan antibiotik dengan spektrum luas dengan lama penggunaan antibiotik yaitu 2 sampai 3 hari (Kemenkes RI, 2011).

Hasil evaluasi penggunaan antibiotik dengan metode Gyssens diperoleh bahwa dari 40 peresepan antibiotik untuk terapi tifoid sebanyak $40 \%$ peresepan antibiotik yang tergolong penggunaan rasional (kategori 0) dan 60\% lainnya yang tergolong penggunaan tidak rasional (kategori I-VI). Penggunaan antibiotik yang tidak rasional didominasi oleh kategori IIIA sebanyak $40 \%$ dikarenakan terdapat peresepan antibiotik yang durasi penggunaannya melebihi pedoman penggunaan antibiotik di rumah sakit pada penelitian ini. Ketiga jenis antibiotik pada penelitian ini merupakan terapi empiris sehingga penggunaannya direkomendasikan 2-3 hari (Kemenkes RI, 2011). Hal ini juga mempengaruhi hasil evaluasi pada kategori IIIB sebesar 5\%. Penggunaan antibiotik yang tergolong kategori IVA ditujukan pada penggunaan azitromisin. 
DOI : https://doi.org/10.24843/JFU.2020.v09.i01.p06

pISSN: 2301-7716; eISSN: 2622-4607

Jurnal Farmasi Udayana, Vol 9, No 1, Tahun 2020, 32-39

Berdasarkan pedoman penggunaan antibiotik di rumah sakit pada penelitian ini, terdapat antibiotik yang lebih efektif seperti seftriakson dan levofloxacin. Antibiotik golongan sefalosporin dan fluorokuinolon tersebut merupakan antibiotik yang disarankan saat ini dikarenakan tingginya Multiple Drug Resistance pada lini pertama seperti golongan penisilin, kloramfenikol, dan trimethoprim-sulfametoksazol (Melarosa dkk., 2019). Pada penelitian ini terdapat pula antibiotik yang tergolong kategori IVB dikarenakan terdapat 2 kasus peresepan antibiotik yang menyebabkan pasien mengalami alergi. Menurut pedoman penggunaan antibiotik di rumah sakit pada penelitian ini, interval penggunaan antibiotik seftriakson, levofloxacin, dan azitromisin adalah tiap 24 jam. Berdasarkan hasil evaluasi, terdapat 2 kasus peresepan tidak tepat interval yaitu antibiotik yang diberikan tiap 12 jam, sehingga digolongan ke dalam kategori IIB sebesar 5\%.

Kuantitas penggunaan antibiotik berdasarkan metode ATC/DDD menunjukkan bahwa penggunaan seftriakson memiliki nilai DDD/100 patient days tertinggi pada tahun 2019 sebesar 83,80 yang artinya dari 100 pasien setiap harinya ada 83-84 pasien yang mendapatkan seftriakson sebesar 2 gram per hari. Penelitian serupa yang dilakukan di Rumah Sakit Panti Rini Yogyakarta menunjukkan bahwa seftriakson merupakan antibiotik terapi tifoid yang paling banyak digunakan dengan nilai DDD/100 patient days sebesar 48,99 (Nonita, 2019). Berdasarkan Tabel 5, diperoleh bahwa nilai DDD/100 patient days untuk ketiga jenis antibiotik melebihi standar DDD menurut WHO. Banyaknya penggunaan antibiotik yang berlebihan dapat menyebabkan nilai DDD yang tinggi yang dipengaruhi oleh besarnya jumlah nilai gram antibiotik yang digunakan (WHO, 2019). Beberapa faktor yang diduga mempengaruhi kuantitas penggunaan antibiotik diantaranya terdapat frekuensi penggunaan yang tinggi dan lama penggunaan antibiotik yang melebihi standar pedoman penggunaan antibiotik. Nilai DDD/100 patient days yang lebih tinggi dan tidak sesuai dengan nilai standar WHO menunjukkan bahwa peresepan antibiotik tidak selektif sehingga akan berpengaruh pada rasionalitas penggunaan antibiotik (Carolina, 2014).

\section{KESIMPULAN}

Berdasarkan hasil evaluasi kualitas penggunaan antibiotik dengan metode Gyssens, pemberian antibiotik di salah satu rumah sakit pemerintah Provinsi Bali tahun 2019 sebanyak $40 \%$ termasuk dalam kategori 0 yaitu penggunaan antibiotik yang rasional. Sebanyak 60\% lainnya termasuk ke dalam penggunaan antibiotik yang tidak rasional (kategori I-VI) yang didominasi oleh kategori IIIA sebanyak 16 peresepan, kemudian pada kategori IIB, IIIB, IVA, IVB sebanyak 2 peresepan untuk masing-masing kategori tersebut. Berdasarkan hasil evaluasi kuantitas penggunaan antibiotik dengan metode ATC/DDD, ketiga jenis antibiotik yaitu seftriakson, levofloxacin, dan azitromisin memiliki nilai DDD/100 patient days yang melebihi standar WHO. Nilai DDD/100 patient days pada masing-masing antibiotik yaitu seftriakson sebesar 83,80; levofloxacin sebesar 27,47; dan azitromisin sebesar 3,52 DDD/100 patient days.

\section{UCAPAN TERIMAKASIH}

Terimakasih penulis ucapkan kepada dosen pembimbing serta semua pihak dari Instalasi Rekam Medis di salah satu rumah sakit pemerintah Provinsi Bali yang telah memberikan segala bentuk bantuan serta dukungan selama penelitian ini berlangsung.

\section{DAFTAR PUSTAKA}

Adiputra IKGT, Somia IKA. 2017. Karakteristik Klinis Pasien Demam Tifoid di RSUP Sanglah Periode Waktu Juli 2013-Juli 2014. E-Jurnal Medika. Vol 6(11): 98-102.

Alam A. 2011. Pola Resistensi Salmonella enterica Serotipe Typhi, Departemen Ilmu Kesehatan Anak RSHS Tahun 2006-2010. Sari Pediatri. Vol 12(5): 296-301.

Carolina M. 2014. Evaluasi Penggunaan Antibiotika dengan Metode DDD (Defined Daily Dose) pada Pasien Anak di Rawat Inap Bangsal Inska II RSUP Dr. Sardjito 
DOI : https://doi.org/10.24843/JFU.2020.v09.i01.p06

pISSN: 2301-7716; eISSN: 2622-4607

Jurnal Farmasi Udayana, Vol 9, No 1, Tahun 2020, 32-39

Yogyakarta Periode Januari-Juni 2013. Skripsi. Fakultas Farmasi Universitas Sanata Dharma Yogyakarta.

Dewi LA. 2018. Evaluasi Penggunaan Antibiotik pada Pasien Demam Tifoid Rawat Inap di Rumah Sakit Islam Klaten Tahun 2017. Skripsi. Fakultas Farmasi Universitas Setia Budi Surakarta.

Dewi NMDP, Illahi RK, Lyrawati D. 2019. Analisis Cost-Effectiveness Penggunaan Antibiotik Kloramfenikol, Seftriakson, dan Sefiksim Sebagai Terapi Demam Tifoid Anak. Pharmacentical Journal of Indonesia. Vol 5(1): 5359.

GDB Typhoid and Paratyphoid Collaborators. 2017. The Global Burden of Typhoid and Paratyphoid Fevers: A Systematic Analysis For The Global Burden of Disease Study 2017. The Lancet Infectious Disease. Vol 19: 369-381.

Hasnawati, Asdar F, Mahyudin. 2014. FaktorFaktor yang Berhubungan dengan Lama Hari Rawat Pasien Demam Tifoid di Ruang Rawat Inap RSUD Pangkep. Jurnal Ilmiah Kesehatan Diagnosis. Vol 5(5):586-593.

Kemenkes RI. 2011. Peraturan Menteri Kesehatan Republik Indonesia, Nomor 2406/Menkes/Per/XII/2011, tentang Pedoman Umum Penggunaan Antibiotik. Jakarta: Kementerian Kesehatan Republik Indonesia.

Kemenkes RI. 2015. Peraturan Menteri Kesehatan Republik Indonesia Nomor 8 Tabun 2015 tentang Program Pengendalian Resistensi Antimikroba di Rumah Sakit. Jakarta: Kementerian Kesehatan Republik Indonesia.

Megawati F. 2015. Persentase Kerasionalan Penggunaan Antibiotik pada Pasien Demam Tifoid Anak di Instalasi Rawat Inap Rumah Sakit Tk.II Udayana Denpasar. Medicamento. Vol 1(1): 26-30.

Melarosa PR, Ernawati DK, Mahendra AN. 2019. Pola Penggunaan Antibiotika pada Pasien Dewasa dengan Demam Tifoid di RSUP Sanglah Denpasar Tahun 2016-2017. E-Jurnal Medika. Vol 8(1): 12-14.
Nonita R. 2019. Evaluasi Penggunaan Antibiotika pada Kasus Demam Tifoid di Rumah Sakit Panti Rini Yogyakarta. Skripsi. Fakultas Farmasi Universitas Sanata Dharma Yogyakarta.

Pani S, Barliana MI, Halimah E, Pradipta IS, Annisa N. 2015, Monitoring Penggunaan Antibiotik dengan Metode ATC/DDD dan DU 90\%: Studi Observasional di Seluruh Puskesmas Kabupaten Gorontalo Utara. Jurnal Farmasi Klinik Indonesia, Vol 4(4): 275-280.

Pattatan S. 2017. Evaluasi Penggunaan Antibiotik pada Pasien Demam Tifoid Rawat Inap Rumah Sakit Stella Maris Makassar pada Tahun 2016. Skripsi. Fakultas Farmasi Universitas Sanata Dharma Yogyakarta.

Pramitasari OP. 2013. Faktor Risiko Kejadian Penyakit Demam Tifoid pada Penderita yang Dirawat di Rumah Sakit Umum Daerah Ungaran. Jurnal Kesehatan Masyarakat. Vol 2(1): 1-10.

Purba IE, Wandra T, Nugrahini N, Nawawi S, Kandun N. 2016. Program Pengendalian Demam Tifoid di Indonesia: Tantangan dan Peluang. Media Litbangkes. Vol 26(2): 99-108.

Sitompul F, Radji M, Bahtiar A. 2016, Evaluasi Penggunaan Antibiotik dengan Metode Gyssens pada Pasien Stroke Rawat Inap di RSUD Koja secara Retrospektif (Periode KJS dan BPJS). Jurnal Kefarmasian Indonesia. Vol 6(1): 30-38.

Tjay TH, Rahardja K. 2007. Obat-Obat Penting Khasiat, Penggunaan dan Efek-Efek Sampingnya. Jakarta: PT. Elex Media Komputindo.

WHO. 2018. Immunization, Vaccines and Biologicals: Typhoid, viewed $10 \quad$ September2019, $<$ https://www.who.int/immunization/disease s/typhoid/en/>.

WHO. 2019. Guidelines for ATC Classification and DDD Assignment 2019. Oslo: WHO Collaborating Centre for Drug Statistics Methodology.

\section{This work is licensed under a Creative Commons Attribution 4.0 International License}

